\title{
AS FESTIVIDADES E A ALIMENTAÇÃO ENQUANTO ELEMENTOS DE IDENTIDADE CULTURAL NO MUNICÍPIO DE SILVEIRA MARTINS - RS ${ }^{1}$
}

\author{
Elvis Albert Robe Wandscheer ${ }^{2}$, Michele Lindner ${ }^{3}$, Marcelino de Souza ${ }^{4}$
}

\section{Resumo}

O presente trabalho busca visualizar as festividades e a alimentação enquanto elementos de identidade cultural presentes nas comunidades de origem ítalo-brasileiras, no município de Silveira Martins, localizado no estado do Rio Grande do Sul, Brasil. Metodologicamente, a pesquisa é de cunho descritivo, realizando-se abordagens de cunho qualitativo, que juntamente com fontes secundárias e observações de campo geraram subsídios aos resultados obtidos. As considerações finais apontam para reflexões sobre a estreita relação entre a produção e o meio rural, a gastronomia e as inter-relações pessoais, juntamente com os laços históricos da colonização italiana na constituição cultural de sua identidade.

Palavras-Chave: Festividades - Alimentação - Identidade.

\begin{abstract}
The present work aims to viasualize the celebrations and food supplies as a cultural identity element present in the italian-brazilian communityes in Silveira Martins city, localized in Rio Grande do Sul state, Brazil. Methodologically, we realized a descritive search, where we performed qualitative approaches, that together with secondary fonts and field observations gave assistance to the obtained results. The final considerations conduct to reflexions concerning the strict relationships between the production and the rural medium, the cookery, and the inter-personal relationships, that together with the italian colonization history contribute to their cultural identity.
\end{abstract}

Key-Words: Celebrations - food supplies - identity

\footnotetext{
${ }^{1}$ O presente trabalho é produção integrada a um sub-projeto da pesquisa denominada: $A$ Demanda $e$ as perspectivas do turismo nos municípios da região da Quarta-Colônia-RS, que contou com o apoio financeiro da Fundação de Amparo a Pesquisa do Estado do Rio Grande do Sul - FAPERGS.

${ }^{2}$ Autor, Acadêmico do Curso de Mestrado em Desenvolvimento Rural - PGDR da Universidade Federal do Rio Grande do Sul - UFRGS. E-mail: elvishz@yahoo.com.br

${ }^{3}$ Co-Autora: Doutoranda em Geografia, Universidade Estadual Paulista - "Julio de Mesquita Filho" - UNESPRio Claro. E-mail: michelindner@gmail.com

${ }^{4}$ Orientador, Professor da Faculdade de Ciências Econômicas e do Curso de Mestrado em Desenvolvimento Rural - PGDR da Universidade Federal do Rio Grande do Sul - UFRGS. E-mail: marcelino.souza@uol.com.br
} 


\section{Introdução}

O município de Silveira Martins é um dos nove municípios que constituem a chamada região da Quarta Colônia. Em sua totalidade, estes municípios possuem uma característica eminentemente rural, ao serem compostos por pequenas propriedades. E, mesmo que dois destes tenham sua colonização efetuada majoritariamente por imigrantes alemães, os demais contemplam a descendência de colonizadores italianos que chegaram a esta porção do território gaúcho no final do século XIX, sendo oriundos, em grande parte, de fluxos populacionais de outras colônias italianas no estado, sobretudo de Caxias do Sul, como afirma Souza (2000, p.93).

Em 1875, chegaram ao Rio Grande do Sul os primeiros imigrantes italianos, que se estabeleceram na encosta superior da serra nordeste, ocupando os divisores de águas, através também de pequenas propriedades, onde ficaram praticamente isolados... a Colônia de Caxias do Sul, que passaria a funcionar como centro de irradiação para outras colônias...

Dadas as características das propriedades, em geral pequenas unidades produtivas (em média 20 hectares por unidade familiar, minimizada ainda mais, dada a topografia que em sua grande maioria dificulta o cultivo agrícola), trata-se de uma agricultura com reduzida dimensão de exploração, que visa principalmente o autoconsumo e o abastecimento de mercados locais. Estas propriedades demandam pouco recurso de mão-de-obra e a anterior característica de famílias com numerosos filhos faz com que, ao longo do tempo, os descendentes destes italianos fosse migrando para os centros urbanos próximos, sobretudo para Santa Maria, o maior núcleo urbano situado nas proximidades da região. Tal migração fora acelerada nas décadas de 60 e 70, encontrando na década de 80 certa acentuação.

Diante desta realidade sentiu-se a necessidade de introduzir ações que buscassem minimizar impactos, e dadas as peculiaridades locais, vislumbrou-se as mesmas enquanto eminentes potencialidades locais, ou seja, a valorização daqueles costumes e hábitos que norteavam o cotidiano dos produtores no meio rural, conforme menciona Itaqui (2002, p. 23):

\footnotetext{
A partir da década de 80 , quando os problemas se acentuaram foram criados vários projetos, principalmente de cunho cultural e ambiental, tentando valorizar o patrimônio cultural, natural e histórico e encontrar saídas para a crise que atingia todos os municípios.
}

Essa iniciativa fora o início do processo que redundou, em 1995, na criação do Projeto de Desenvolvimento Sustentável da Quarta Colônia do RS (PRODESUS), composto por 
quatro subprojetos integrados, dentre os quais está o projeto ao qual se relaciona o presente trabalho: O Desenvolvimento do Turismo Ecológico, Rural e Cultural.

Apesar da criação deste subprojeto, as ações efetuadas no âmbito das iniciativas turísticas não perpassaram as esferas locais de abrangência, bem como sua estruturação no espaço não perfazem a extrapolação do mesmo, assim, perpetuam-se no âmbito local hábitos historicamente difundidos e que atravessam gerações familiares, sobretudo no tocante às formas de produção agrícola, as manifestações culturais, as festividades e a gastronomia. Diante desta realidade, trata-se, portanto, de um espaço contextualizado numa dada cultura, neste caso a cultura ítalo-brasileira:

O espaço é suporte das atividades produtivas dos grupos humanos. Inicia-se pela exploração dos meio naturais... O espaço humanizado é igualmente organizado para permitir aos homens viverem como lhes convêm num contexto cultural (CLAVAL, 2001, p. 287-291).

Portanto, as motivações que perfazem o incentivo de visitação ao local contemplam o resgate na história cultural do município e/ou ainda, mais especificamente, de comunidades deste. Este é um traço bastante característico, principalmente nas colônias de imigração italiana e alemã no Rio Grande do Sul, onde a utilização de receitas passadas de geração em geração, por exemplo, não somente através de pratos quentes a serem consumidos no âmbito local, mas também queijos, cucas, compotas, vinhos, dentre outros, contemplam parte importante da cultura, da história destes povos. Chamando a atenção para alguns pratos e a relevância da cozinha italiana, Fagliari (2005, p. 116) destaca que:

Dentre os imigrantes é possivel afirmar que os italianos influenciaram os hábitos
alimentares brasileiros... A maior herança deixada pelos italianos foi no campo das
massas, as quais foram adaptadas ao gosto brasileiro, tornando-se muito populares
no país. Ainda podem ser citados molhos, sopas, polenta, carnes a milanesa,
beringela e pizzas como contribuições marcantes desse grupo.

Nesse sentido, os aspectos produtivos locais diretamente ligados aos hábitos alimentares conduzem a uma determinada configuração que se dá não somente na estruturação das festividades locais, mas sim, em todos os hábitos cotidianos, uma vez que todos esses aspectos estão diretamente interligados, de forma a perfazer os costumes históricos pelas quais se construiu o espaço e fixaram-se os antepassados dos habitantes do município de Silveira Martins. Assim, Cristóvão (2002, p. 81) enfatiza que “...o reconhecimento de que o espaço rural é bem mais do que um simples fornecedor de matérias primas. É, no fundo, um espaço multifuncional. Alguns autores referem mesmo que o espaço rural tem hoje uma nova legitimidade, identitária...". 
Portanto, este município em seus espaços rurais, em todas suas comunidades, a exemplo da assertiva acima, muito além de fornecedores de matérias primas, juntamente com a atividade e as paisagens agrícola, produtos e hábitos gastronômicos, possuem muitos outros aspectos que interagem e se inter-relacionam, perfazem e legitimam a sua identidade, ou seja, a forma pelas quais os indivíduos construíram e ainda constroem os seus valores simbólicos.

Neste sentido, Cristóvão (2002, p. 82) destaca o meio rural em vários elementos, recursos e valores potenciais que o mesmo contempla:

\begin{abstract}
Assumir o mundo rural como espaço multifuncional implica uma lógica de identificação e valorização dos recursos existentes, do chamado potencial endógeno (cujo aproveitamento exige a combinação/articulação com recursos externos). Assim, quando hoje falamos de recursos rurais, falamos de um amplo espectro de elementos, que inclui antigos, actuais e novos produtos agrícolas e agro-industriais (alimentares e não alimentares), paisagem, fauna e flora, rios e albufeiras, montanhas e vales, caça e pesca, rochas e minerais, águas minero-medicinais, património arqueológico e histórico, arquitectura popular, tradições culturais, artesanato, gastronomia, linhas férreas, solares e casas rurais, miradouros, parques e reservas naturais, feiras, festas e romarias, música, teatro e poesia popular.
\end{abstract}

No domínio do debate em torno do meio rural, sua valorização, identidade e simbologias peculiares, encontram-se as manifestações de toda uma gama de ações cotidianas carregadas de valores próprios e heranças históricas, na qual se fundamenta a existência desses espaços no imaginário coletivo, que expressam em suas iniciativas, sejam elas individuais ou coletivas, o pertencimento ao grupo, à comunidade. Um exemplo desse pertencimento se dá nas festividades, onde se busca a contemplação das formas pelas quais, os sujeitos vêem e elaboram o "seu" território 5 . O exemplo mais nítido (ainda que não único) fixa-se nos produtos agroalimentares, apresentados com exuberância nesses eventos, mas que também são amplamente valorizados e apreciados mesmo no dia-a-dia das comunidades ${ }^{6}$, ainda que não em tamanha quantidade, combinações e abundância.

\footnotetext{
${ }^{5}$ Por território entende-se geralmente a extensão apropriada e usada. Mas o sentido da palavra territoriabilidade como sinônimo de pertencer aquilo que nos pertence... esse sentimento de exclusividade e limite ultrapassa a raça humana e prescinde a existência do estado... (SANTOS, 2003, p. 19).

${ }^{6} \mathrm{La}$ acción de alimentarse, de carácter tan personal, em la que nadie puede suplantar a ningún outro y que resulta indispensable para la supervivencia de cada uno, es simultáneamente individual y colectiva. Los humanos no viven aislados sino insertos em la interación de um individuo intervienen, colaboran e interfieren muchos otros, em general desconocidos, em âmbitos diferentes y dispersos...Desde los sectores de la producción alimentaria (semillas, fertilizantes, plaguicidas, maquinaria), de la transformación (modificación, implementación, conservación, envasado)... hasta la fase final de aquisición... (MILLÁN, 2002, p. 279-280).

Essas ações no caso do espaço em estudo se dão no âmbito dos espaços comunitários do município, inicialmente no núcleo familiar para posteriormente somarem-se a esforços conjuntos desde auxílios nas distintas atividades do processo produtivo até o empréstimo de ferramentas, maquinários, insumos ou até produtos in natura, contemplando a identificação e valorização do meio pelos indivíduos, bem como dos recursos ali existentes.
} 
Considerando estes aspectos, o presente trabalho tem como objetivo visualizar as festividades e alimentação enquanto elemento de identidade cultural no município de Silveira Martins - RS, de forma a destacar as manifestações pelas quais estes elementos constroem a identidade daquela população e, em que contexto as festividades e práticas alimentares integram e interagem no âmbito social e na dinâmica do cotidiano da população, que mesmo na porção urbana conserva uma característica peculiar e um modo de vida herdado de seus antecedentes italianos.

\section{Metodologia}

O trabalho em questão teve em seu plano de pesquisa a realização de uma abordagem relativa a festividades e práticas alimentares, juntamente com outros elementos peculiares no município de Silveira Martins-RS, de forma a visualizar a identidade cultural e as simbologias dos habitantes locais.

Para tanto, realizou-se uma pesquisa de cunho descritivo, efetuando abordagens de cunho qualitativo, que juntamente com as fontes secundárias e observações de campo geraram subsídios ao desenvolvimento do trabalho.

A realização da saída de campo se deu nos dias 1 de dezembro de 2006, na III Fesbata, 10 de fevereiro de 2007, na II Festival da Uva e das Águas. Ainda, nos dias 16 e 17 de junho, as entrevistas foram realizadas diretamente com os habitantes locais. Neste trabalho, efetuouse a aplicação de instrumentos de pesquisa (entrevistas) que pudessem captar informações referentes à identidade e simbologias dos habitantes, bem como dos parentescos que visitavam o local, sendo, portanto, caracterizados como turistas ${ }^{7}$. Aplicou-se ainda, um roteiro específico para a obtenção de informações junto à organização dos eventos e dos representantes públicos municipais presentes.

Em razão de a pesquisa adotar um caráter qualitativo, teve-se o especial cuidado com a representatividade das respostas frente ao grupo, ou seja, os habitantes da comunidade.

Como as informações recolhidas estavam identificadas de maneira escrita textualmente, foi necessário realizar a reorganização do material coletado, tendo em vista sua interpretação, transcrevendo-se as respostas a fim de facilitar a análise posterior.

\footnotetext{
${ }^{7}$ Por turista, utilizou-se a abordagem conceitual de Masina apud OMT (2002, p. 16), na qual, os mesmos são caracterizados como: "...todas as atividades que realizam as pessoas durante suas viagens e permanências em lugares diferentes de onde residem habitualmente, por um período de tempo consecutivo inferior a um ano, tendo como objetivos o ócio, negócios e outros.
} 
Dessa forma, os dados e as informações obtidas nos trabalhos de campo, em conjunto com outros dados secundários (livros, artigos, folders e materiais de divulgação da área em estudo) permitiram alcançar os resultados presentes neste trabalho.

\title{
3. Revisão Bibliográfica
}

Habitualmente tem-se que a alimentação é uma ação realizada com o intuito de suprir uma necessidade fisiológica humana. Contudo, na ação "alimentar-se" estão contidas outras representações, como descreve Alvarez e Pinotti (2000, p. 257):

\begin{abstract}
La comida costituye un medio casi universal para expresar sociabilidad y hospitalidad. La proximidad o estrechez de las relaciones sociales entre las personas puede expresarse mediante los tipos de alimentos y comidas que toman juntos, así como por la frecuencia de esas comidas.
\end{abstract}

A alimentação, desde a combinação e o preparo até o consumo, exprime relações sociais entre as pessoas, fazendo parte, portanto, da constituição de identidades e distinções locais. Flandrin e Montanari (1998, p. 26) fazem a seguinte assertiva referente aos onívoros:

\begin{abstract}
Em que e a partir de quando o homem se distingue do animal em sua alimentção?...O que se pode dizer é que os homens sempre foram onívors e mais ou menos inclinados, de acordo com as épocas e as regiões em que viveram a comer alimentos vegetais ou animais. De qualquer modo, não se pode dizer que essa característica marca o início da história humana, pois antes mesmo da primeira aparição dos hominídeos, já existiam primatas onívoros...
\end{abstract}

Outros enfoques, ainda, dão continuidade na abordagem quanto à importância e a identidade representada pelo ato de comer, conforme Da Matta (1987, p. 22):

O fundamental é que o ato de comer cristaliza estados emocionais e identidades sociais. Fora do país posso tornar uma comida regional emblemática da identidade nacional; mas dentro do Brasil identifico muitas regiões e até famílias pelo modo com que preparam e servem certos alimentos.

Portanto, distinções, combinações e preparos diversificados no ato de alimentar-se possuem um cunho identitário, que pode ser apropriado, rejeitado ou adaptado num local distinto. Este envolve toda e qualquer alimentação, bem como o hábito de fazê-lo, a localização dos indivíduos, as possibilidades e as necessidades de consumir ou não determinado produto. Assim, extravasando a simples necessidade humana, mas voltando-se para a cultura e sua expressão no tempo, Da Matta (1987, p. 22) faz a seguinte colocação: 
claramente um acto cultural. E é tanto mais verdade isto quanto maiores foram os períodos de isolamento das comunidades...

A distância do centro urbano, aliada à dificuldade de comunicação existente no passado, fez com que a cultura e, consequentemente, a alimentação no meio rural, permanecessem permeadas por saberes e práticas diferenciadas que acabam por identificá-las nas próprias relações sociais, preservando-se enquanto comida ideal e real, antiga e atual (RAMOS, 2007).

Assim, a mesma autora trata da valorização que tem sido auferida do mundo rural pelo urbano, destacando-se a preocupação do segundo para com a realidade vivenciada no primeiro, ou seja, questões como a conservação ambiental e cultural passa sim, a ter relevância na forma de visualizá-la:

Nesse sentido, ocorre atualmente um movimento de valorização do rural por parte de grupos urbanos, a partir do qual a comida da roça é ressignificada e revitalizada. Seu consumo, então, passa a ser percebido como um caminho de contrução de modelos de desenvolvimento rural que promovam conservação ambiental e valorização da cultura rural (RAMOS, 2007, p. 156).

No bojo de elementos dessa valorização (principalmente quando reportando-se a esfera alimentícia) estão os eventos gastronômicos. Fagliari (2005, p. 62-63) aborda-os denotando as estreitas relações que, comumente, se dão:

Um tipo bastante comum de evento gastronômico é aquele voltado para um produto, ou ingrediente específico. Essas festas variam muito dependendo do local que se realizam, pois estão muito relacionadas com a produção local... Também há eventos que tratam de um tipo de estabelecimento de alimentação ou de culinária específico... Podem ser citados, ainda, eventos voltados para a culinária típica de uma localidade... Eventos de bebidas, gêneros alimentícios ou pratos tradicionais de um país ou localidade...

Assim, enquanto elementos culturais, as festividades e a alimentação contemplam elementos ímpares, se tratando de expressão, simbologia e sentimento de pertencimento a uma dada sociedade. Alvarez e Pinotti (2000, p. 257) fazem a seguinte afirmação quanto aos alimentos:

...os hábitos alimentares e as maneiras à mesa serviram para moldar os estereótipos nacionais...Visto do estrangeiro, a cozinha italiana reduz-se, freqüentemente, às massas e às pizzas, específicas certo, mas que fazem esquecer o que todo o resto da refeição tem de comum...

A partir da valorização das especificidades no âmbito dos hábitos alimentares, buscouse apontar a relevância da cozinha frente a elementos culturais, que através de suas relações contemplam importantes elementos de um dado local, indo ao encontro da temática deste 
trabalho, ou seja, a alimentação enquanto fator de identidade cultural no município de Silveira Martins-RS.

\section{As Festividades e a Alimentação em Silveira Martins-RS}

As festividades realizadas no município de Silveira Martins possibilitam a reconstrução dos hábitos e costumes do passado daqueles imigrantes italianos que colonizaram o território. Conforme expressa o depoimento de um habitante local, através da seguinte assertiva:

Essas festas sempre foram comuns entre as comunidades próximas aqui de Silveira Martins, nossos pais, avós e bisavós reuniam-se com os vizinhos e comiam as mesmas coisas que temos no filó Italiano de hoje, a diferença é que agora conseguimos abranger muito mais gente, até mesmo parentes que foram embora do município, mas que voltam para nos visitar, participar da festa e saborear a comida.

No bojo de elementos que contemplam a importância das representações sociais existentes nestas festividades, encontra-se uma extensa lista de elementos que envolvem implicações naturais, socioeconômicas e, sobretudo culturais, portanto:

\footnotetext{
Falar de práticas alimentares envolve múltiplos aspectos de caráter psicológico, biológico e sócio-cultural, visto ser um fenômeno que abrange distintas dimensões, entre as quais as que envolvem o espaço social alimentar. Falar de práticas, portanto, também é discutir não apenas o que se planta, mas as formas de cozinhar, apresentar os pratos à mesa, preparar rituais de consumo e eventos comemorativos que justificam inclusive as preferências individuais e coletivas (FLORES; SILVA, 2006, p. 197).
}

Os preparos abrangem especificidades em todos os pratos. As questões em torno do produto contém uma série de fatores e serão abordados posteriormente. Porém, quando se trata da questão da panela utilizada no preparo, conforme depoimentos coletados juntamente ás cozinheiras nos espaços destinados ás cozinhas das festas, existe uma ambigüidade eminente entre o "elogiado" e o "utilizado".

Ao mesmo tempo em que destacam o papel da panela de ferro utilizada antigamente e o quão saboroso eram os pratos elaborados nestas panelas, ao comentarem quanto às suas práticas atuais, as mesmas disseram utilizar panelas de alumínio, alegando os ganhos quanto à praticidade no manuseio e transporte e maior facilidade na higienização das mesmas. O papel da panela nesse contexto reporta a razões simbólicas quanto a escolha do alumínio, conforme Ramos (2007, p. 80):

Nesse sentido, o alumínio na cozinha pode ser entendido como uma evidência do processo de modernização das famílias. Em um momento histórico em que o "ser 
moderno" é um projeto de vida predominante, elementos que simbolizam modernidade tendem a ser valorizados.

Diante destes aspectos, a importância da comida frente aos festejos encontra-se, sobretudo, na auto-afirmação, exaltação de sua história ao longo da colonização daquele território, mantendo o orgulho visivelmente perceptível, tanto nos depoimentos quanto nas manifestações dos indivíduos, como exemplifica o depoimento a seguir:

Tudo isso aqui são coisas nossas, vocês não devem ver isso lá de onde vocês vêm, porque essas tradições são nossas, diferente das festas de italianos que fazem em outros lugares, já fui e não gostei, prefiro nossos festas aqui. Nestas festas temos tudo que sempre foi da nossa terra, tudo que ajudou as nossas famílias que chegaram aqui a desbravarem esses matos, abrindo picadas e dando o alimento a todos que aqui chegaram e escolheram esse lugar para viver e criar seus filhos.

Mesmo diante das características acima destacadas, os representantes públicos locais chamam a atenção para o fato de procurarem englobar outros visitantes aos festejos. Porém, o que se percebe, desde as programações, são objetivos claramente voltados especificamente àquelas famílias ítalo-brasileiras como, por exemplo, a realização de missas, palestras aos produtores sobre as histórias e as técnicas de produção na lavoura de batata, além da apresentação da banda municipal com as canções que integram a cultura local e que são transmitidas de geração a geração.

Estas programações acabam dirigindo-se mais acentuadamente aos habitantes locais e seus parentes, na figura de turistas, perfazendo festividades tipicamente locais, sobretudo pela ligação existente entre a identidade do grupo social (população local) e as mesmas. Um exemplo claro desse fenômeno e a relevância dos produtos, demonstrada nas expressões e depoimentos dos indivíduos, o quanto cada um deles representa, seja enquanto importante complemento de renda a propriedade, ou então, constituindo-se até mesmo em alguns casos, como produto principal dos estabelecimentos rurais.

Mas muito além do simples valor econômico, os produtos constituem-se também em alimento (no caso do auto-consumo), contemplam a ocupação diária, além de carregar consigo os resultados do labor dos produtores. Levam consigo, portanto, o orgulho destes, que é exibido ao longo das festividades, e uma das formas na qual o mesmo espelha seu cotidiano, sua vida. Esse fato pode ser observado nas exibições de produtos efetuados nas festividades e na forma com que eles montam e discorrem sobre os mesmos. 

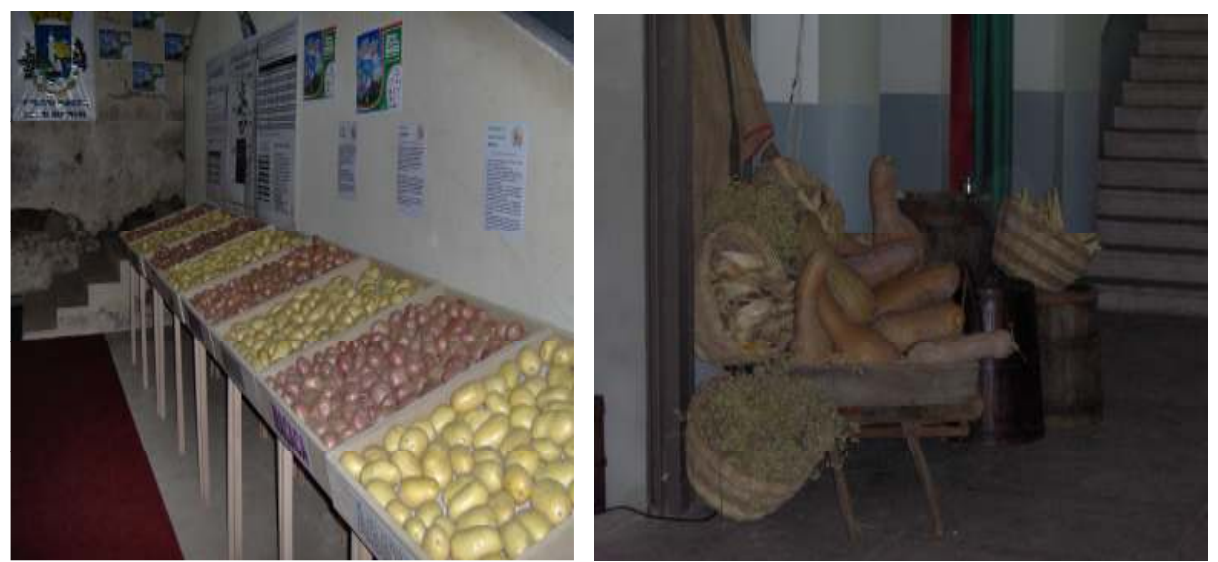

Figura 1: Imagens de exposições de produtos produzidos pelas comunidades locais

Nesse sentido, visualiza-se a produção do meio rural, mas muito além de alternativa econômica. Tem-se aqui uma manifestação da ligação entre atividade produtiva, produtos, produtores(as) e família(s) envolvidas no processo, perfazendo o sentido de identidade, pertencimento.

Este elemento vem ao encontro de características eminentes de festividade local, na qual pode ser vislumbrada já em sua fase de elaboração, através das instalações das festividades (eventos). Faz-se uso de salões de festas de igrejas, tendo em seu entorno capelas, santuários, basílicas e a própria igreja da comunidade, acentuando o caráter ítalo-brasileiro, na qual são conservados costumes que perpassaram gerações e não inserem-se nos padrões dos moldes capitalistas atuais de oferta turística.

O caráter religioso vigente no âmbito local, sobretudo nas festividades, foi o elemento mais citado nas entrevistas. Sob o signo da imigração italiana buscam a motivação de fé, de hábitos culturais, rememoram aspectos da infância ou dos antepassados, construindo a sua identidade familiar. Retornando à origem ancestral desta evidência a cerca das Colônias Italianas no Rio Grande do Sul, o Arquivo Público e Histórico de Bento Gonçalves (1994, p. 56), efetua a seguinte afirmativa:

A igreja era o centro e a motivação desta reconstrução. Em todos os lugares e por
toda a parte, multiplicaram esses sinais de sua identidade cultural. Tendo conseguido
reconstruir, em sua própria linha colonial, os traços culturais de seus vilarejos, os
imigrantes foram, pouco a pouco, esquecendo sua terra e aceitando alegremente a
nova Pátria.

Peculiar à religiosidade local é não somente a participação em missas e cultos ecumênicos, mas também a participação e/ou no caso das festividades, por exemplo, a reunião familiar em festividades na qual a igreja encontra-se envolvida. É o caso da III Fesbata e do II Festival da Uva e das Águas. 
A identificação de tal situação pode ser vislumbrada através da caracterização dos turistas, que informaram em sua totalidade a origem italiana de descendentes italianos, além do parentesco no espaço local. Assim, as projeções quanto à hospedagem, na maioria das vezes ocorre com pernoite ou sem pernoite em casas de parentes. É interessante apontar a forma como os mesmos se denominam "filhos da terra", forma pela qual os mesmos se vêem ligados aquele espaço, aquela alimentação, costumes e características culturais. Conforme Fagliari (2005, p. 29):

A alimentação é, inegavelmente, um elemento do patrimônio cultural dos povos, afirmação esta que vem adquirindo força com a importância atribuída atualmente aos bens culturais intangíveis. Assim para compreender o posicionamento da alimentação na segmentação do turismo, é preciso compreender qual seu posicionamento em termos de recurso... Outros estudiosos, entretanto, vêem esse recurso de forma mais ampla, considerando sua importante atuação como elemento cultural de um destino e a possibilidade de se uso...

Nesta perspectiva, as festividades locais podem ser vislumbradas enquanto festividades típicas da cultura local, ou seja, voltadas aos padrões ítalo-brasileiro dos colonizadores que ali se instalaram, mantendo sua gastronomia, folclore e outros hábitos peculiares que foram capazes de se manter e se reproduzirem através de gerações, independente de situações políticas ou econômicas, mantendo-se enquanto hábitos, ou "praxe" como se referem os habitantes locais.

\subsection{Mobilização das Comunidades nas Festividades}

A mobilização ocorre quando um grupo de pessoas, uma comunidade, uma sociedade decide e age com um objetivo comum, buscando atingir resultados desejados por todos (TORO; WERNECK, 1997). A mobilização não deve ser uma imposição para a sociedade, mas um convite a contribuir para construir um sonho. Segundo Henriques (2002), mobilizar é tocar a emoção das pessoas, sem, contudo, manipulá-las. Para que ocorra a mobilização é vital que as pessoas participem, para assim poderem tomar decisões e é ao encontro desse entendimento que se dão as articulações dos eventos que serão a seguir abordados, tanto a III Fesbata, quanto o II Festival da Uva e das Águas.

Para os moradores e parentescos que vem ao local integrarem a festividade, a mobilização dos indivíduos se dá muito no sentido de expor (mesmo que sem alterações aos hábitos alimentares da comunidade) sua produção, atividade laboral, aliando tudo à totalidade que perfaz a gastronomia da unidade familiar e de seus enlaces parentais. 
Essa revalorização cultural é dada em grande parcela pelas representações urbanas destes parentes externos ao município, que agora passam a idealizar o campo, não que não ocorra também entre agricultores locais, porém, o "ar" de nostalgia daquele modo de vida mais calmo e saudável do campo e aos moldes antigos reconstroem um imaginário de importante papel no estímulo que move os agentes envolvidos no processo de discussão, preparação e elaboração das festividades. Assim, conforme Cristóvão (2002, p. 85):

\footnotetext{
...as ideias construídas sobre o quotidiano no campo, o contacto com a natureza e as culturas tradicionais, traduzem-se numa revalorização social do rural e do local e induzem uma busca do singular, do específico, do autêntico. O espaço rural ganha, por este meio, um crescente valor simbólico...
}

Por fim, cabe destacar o fato de que aos habitantes locais o resultado econômico não é balizado de forma tão positiva quanto a preparação realizada para ofertar a melhor recepção possível aos parentes que retornam ao local com o intuito de rever familiares, a localidade e as paisagens locais, e contemplam elementos que remetem a um passado com certo ar de nostalgia, como anteriormente citado.

Trata-se, conforme análise de Champagne apud Ramos (2007, p. 115), de uma festa “à antiga" reconstruindo uma tradição local para um público externo ver". Contudo, com uma diferenciação: a de que o público externo em questão trata-se de parentes dos habitantes locais, indivíduos estes que afirmam ainda serem habitantes do local. Ao vislumbrar essa relação, pode-se auferir que a mesma é também, conforme destacada por Champagne apud Ramos (2007), uma festa a festa antiga (da aldeia), onde agricultores tem reações distintas, umas de ver seu passado admirado, ou então o cotidiano ainda presente e observado como se fosse um fantasma.

Nesse sentido, a mobilização é atravessada pelo envolvimento das comunidades em torno de seu objetivo comum, ou seja, a melhor oferta possível de contemplar e transmitir a revalorização do seu espaço, da identidade local e familiar, de forma que a comunidade possui o sentimento de pertencimento a festa.

\section{Fesbata}

A Festa Estadual da Batata (Fesbata) é realizada anualmente no município de Silveira Martins, e já está em sua terceira edição, tendo como objetivo central a valorização dos produtos rurais do município, dentre os quais é dada ênfase a um dos produtos mais cultivados no seu território rural: a batata. 
Muito além da representação deste produto, enquanto valor econômico, o mesmo apresenta-se também como elemento, símbolo de identidade dos habitantes locais com o mundo rural, ou de identificação dos cidadãos com o município. Um informante local efetuou a seguinte colocação quanto à sua percepção acerca da importância da batata à população das comunidades locais.

A batata sempre fora um produto tradicionalmente produzido e consumido entre todas as pessoas de Silveira Martins, porém a mesma nunca foi realmente valorizada... representa uma herança de hábitos que perpassou muitas gerações e só agora começa-se a ver a importância desse produto tipicamente local.

O preparo deste produto se dá de várias formas: bolinhos, nhoques e purês de batata, enquanto formas características de preparo, outras contrastando com estas perfazem a inserção de "preparos modernos", tais como: a batata frita e o pastel de batata. Não significa, no entanto, afirmar que mudanças ocorridas na alimentação venham a abolir um modelo alimentar. Diez Garcia apud Ramos (2007, p. 156), ao abordar a comida da roça, constata:

\footnotetext{
....apesar das mudanças identificadas na alimentação e no mundo rural, a comida da roça, caracterizada por tais saberes e práticas permanece viva. Ainda que permeada por elementos de mudança, mais ou menos presentes nos diferentes contextos de vida das famílias rurais, a comida da roça não é um modelo alimentar passado e extinto... A comida da roça é ideal e real ao mesmo tempo, antiga e atual...
}

O contraste entre a valorização dos preparos acima citados ficou evidenciado nas entrevistas com os habitantes locais, ao afirmarem nos dois últimos pratos haver um "valor menor" à comunidade e sua cultura, dada a menor valorização do sabor e das características do produto, a batata. Tal afirmação demonstra não somente os laços para com os produtos derivados da batata, como também para com a preparação e apresentação do prato ou a transformação do produto (substância) em comida, comida essa, que no caso da Fesbata é voltada a expressão da identidade ítalo-brasileira daquela comunidade.

DaMatta (1987, p.22) faz a seguinte referência, na busca do simbolismo da comida no Brasil:

\begin{abstract}
...Qualquer brasileiro sabe que toda substância nutritiva é "alimento", mas sabe também que nem todo alimento é comida. De fato, para transformar um alimento em comida, é preciso não só o ato crítico do cozimento, mas também o modo pelo qual o alimento é preparado... É a qualidade da "comida", servida com "capricho" e da maneira farta, que vai exprimir sua "consideração" para com o convidado... Mas, além disso, é a "comida" que permite exprimir e destacar identidades que, de acordo com o contexto da refeição podem ser nacionais, regionais, locais ou até mesmo familiares e pessoais.
\end{abstract}

Outros produtos de identidade local, além da batata, que aparecem com significativa importância simbólica aos habitantes locais e aos seus parentes, de acordo com as 
informações obtidas durante as entrevistas são: A cachaça, o licor e o vinho, todos produzidos nos próprios estabelecimentos rurais, dentre os quais, grande parte já efetua a comercialização destes produtos há algum tempo.

Um exemplo deste fenômeno pode ser vislumbrado no caso da família Moro, que fabrica a cachaça desde a aquisição do Moinho, a cerca de 60 anos atrás. O vinho, por sua vez, é o mais comum nas propriedades, porém, como as comunidades possuem um evento especificamente voltado à valorização do vinho (Festival da Uva e das Águas), este não é muito destacado neste evento, inclusive devido à carência atual do produto ${ }^{8}$. O mesmo ocorre durante o Festival da Uva e das Águas, onde o licor e a cachaça não recebem muita ênfase.

Em todos estes produtos pode-se perceber uma homogeneidade no "enrraizamento", realizado através destes para a construção de uma identidade a sua população, identidade esta que perpassa pela colonização italiana do local e chega à atualidade, ainda com os mesmos laços familiares e origem em seu grupo social.

São estes os produtos destacados na presente festividade, que denota a relação existente nas relações locais, seja entre as pessoas e as famílias, seja com a terra, juntamente com os laços históricos tão valorizados e cultuados no local. Significa dizer, portanto, que são nestes produtos e nestas formas de valorizá-los, juntamente com outros elementos culturais que tecem a organização da festividade (como o espaço físico) que estão acentados o pertencimento ao local, a qualidade de vida que vislumbram. Estes são os elementos mais incisivos e valorativos perceptíveis na III Fesbata, e que constituem a importância e o significado da mesma aos habitantes locais.

\section{Festival da Uva e das Águas}

A festa da Uva e das Águas fora realizado pela segunda vez no município de Silveira Martins - RS. Apesar de se tratar apenas da segunda edição, se tem o objetivo de "oficializar" uma festividade que é historicamente realizada uma vez ao ano, sempre nos meses de janeiro e fevereiro, uma vez que a mesma vem ao encontro da busca do proveito que os autóctones fazem das temperaturas mais elevadas do município ao longo do ano. Não por acaso a festa enaltece a importância das águas (córregos e rios ali existentes) no espaço local. Juntamente

\footnotetext{
${ }^{8}$ Os informantes afirmaram haver limitações na quantidade disponível do produto, sobretudo pelo caráter da produção em pequena escala e ao abastecimento voltado ao autoconsumo, juntamente com a prioridade dada ao Festival da Uva e das Águas. Essa realidade será abordada mais adiante no enfoque referente ao vinho.
} 
com as águas, o evento compartilha a valorização da uva e seus derivados, importante produto do município, na qual residem importantes laços familiares vislumbrados na comensalidade dos habitantes.

Diferenciada em alguns aspectos, mas idêntico na essência simbólica representativa de valores, conforme destacado acima, tem-se nessa festividade a acepção da atividade agrícola da uva (que será debatida posteriormente) e da valorização das águas neste espaço ocupado pelos colonizadores italianos que ali chegaram e se instalaram em planícies e vales drenados pelo rio Soturno e seus afluentes, e que hoje perfazem belos atrativos turísticos através dos balneários locais. Contudo, apesar dos balneários apresentarem turistas durante o período, os mesmos disseram não estarem ali participando do evento, ou seja, mesmo estando no local, os mesmos não se inseriram na festividade, tampouco da simbologia da festa da Uva e das Águas.

Evidencia-se, portanto, a decorrência dessa festa enquanto festividade local, elaborada no intuito de valorização da cultura local, mesmo frente às mudanças ocasionadas pela sua oficialização como, por exemplo, a fixação de uma data exata e a busca do poder público municipal em auxiliar a sua realização.

Nesse sentido, a pesquisa de campo desvela na festa o sentimento de pertencimento, valorizados na história (desde a ocupação), na culinária, na produção agrícola, na integração da comunidade com escassas mudanças, mudanças essas que se deram muito mais no plano da oficialização e no marketing, como por exemplo, nos meios de divulgação, agora abarcando jornais e rádios de alcance local, do que na prática, ou seja, na organização da festa tal qual a mesma já era concebida.

A montagem da estrutura física da festa (Figura 2) se deu na capela São Vitor e Santa Corona de Val Feltrina, local que historicamente abriga essa e as demais atividades da comunidade e que, não raro, recebe público de outros distritos, juntamente com descendentes que saíram da localidade, muitos dos quais migraram para municípios maiores em busca de emprego assalariado, mas que mesmo distantes ainda guardam consigo o ideal, o sentimento de pertencimento àquela esfera local, resguardando valores mantidos do seu passado familiar. 


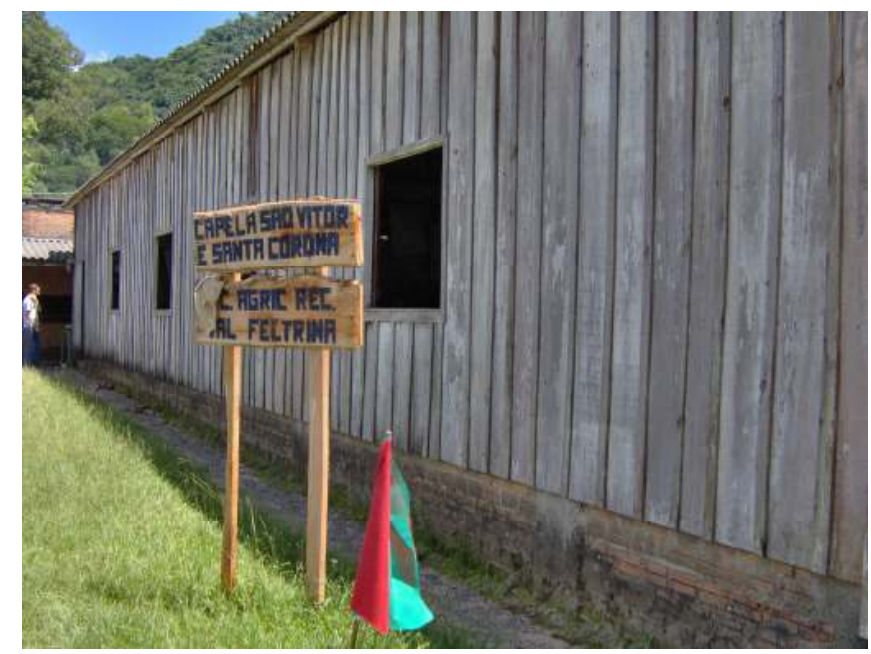

Figura 2: Capela São Vitor e Santa Corona

Ao longo do evento foi de suma importância o fato de que os estabelecimentos existentes no âmbito local das comunidades caracterizam-se pela produção familiar, ainda que com a finalidade principal de abastecimento local, efetuaram a venda de produtos concomitantemente. Os principais produtos são a uva, os sucos de uva e o vinho, porém, outros produtos também aparecem nas "tendas" de vendas como, por exemplo: as cucas, os biscoitos, os bolinhos e os pastéis.

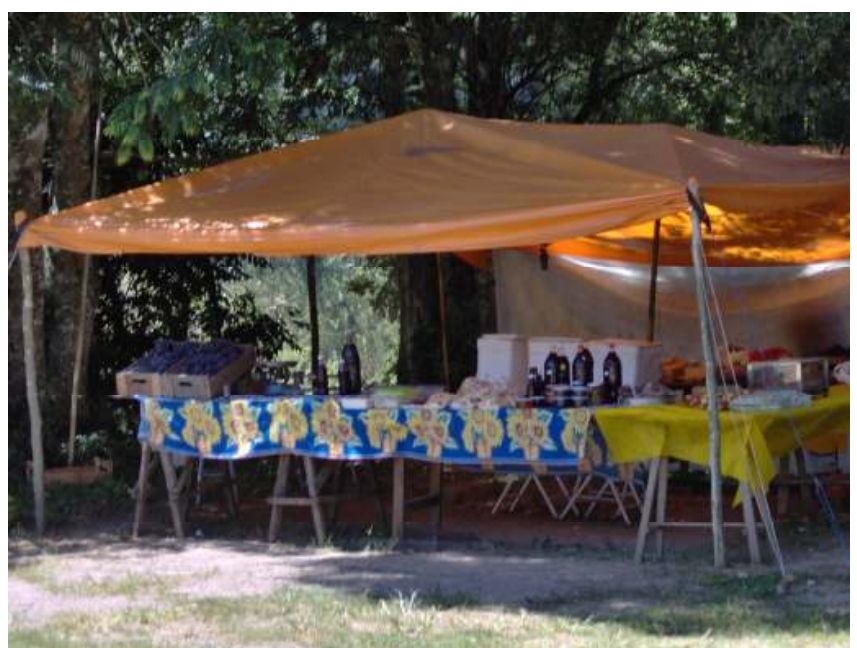

Figura 3: Tenda de Venda na II Festival da Uva e das Águas

Esses estabelecimentos localizam-se nas áreas rurais do município de Silveira Martins e seus proprietários são pequenos produtores familiares, que transformam seus produtos de forma artesanal ou semi-artesanal. Nessa produção familiar, quando questionados os demais membros da família quanto à participação na atividade de produção, os mesmos informaram que participavam direta ou indiretamente, de forma a contemplar a atividade produtiva 
ofertada. Porém, alguns produtores destacaram que quando precisam de auxílio além da família, principalmente em época de colheitas, trabalham num sistema de ajuda mútua, onde os visinhos ajudam e depois são ajudados, num sistema de colaboração que gera resultados a ambas as famílias produtoras.

Em relação aos benefícios trazidos pela produção e comercialização dos produtos, procurou-se saber se os informantes em questão conseguiam identificar benefícios trazidos pela atividade, tanto no aumento da renda da família, quanto a outros tipos de benefícios. Os entrevistados apontaram como maior benefício o fato da produção proporcionar-lhes a continuidade das atividades agrícolas e da rotina produtiva no campo, mantendo quase inalterado o seu cotidiano no meio rural.

\section{Considerações Finais}

No município de Silveira Martins-RS, a exemplo dos demais municípios da região da Quarta Colônia, os usos, costumes e sabores contemplam uma história, laços familiares na qual observa-se a identidade ítalo-brasileira, características eminentes aos grupos, às comunidades localizadas no espaço territorial enfocado.

Essa identidade, no entanto, não se focaliza unicamente na alimentação, pelo contrário, contempla uma gama de fatores, estes que repercutem na gastronomia, seja pelas características de práticas antigas, saberes, gostos e preferências, que por sua vez adquirem grande relevância na elaboração dos festejos. Tais elementos permeiam práticas nas quais estão contidas representações que identificam os habitantes locais ${ }^{9}$.

Outro componente existente no cotidiano e presente nos eventos observados, a III Fesbata e o II Festival da Uva e das Águas, diz respeito às ligações entre as comunidades e a prática religiosa, de forma que estas encontram-se presentes nas festividades e recebam reconhecimento tanto pelo patrimônio material, quanto pelo imaterial.

Nesse sentido, os próprios turistas reportam-se a esses patrimônios do meio em busca dos produtos, paisagens e suas representações, muitas das quais contidas nos laços parentais ali existentes.

\footnotetext{
9 ...as tentativas para decifrar de outro modo as sociedades, penetrando na meadas das relações e das tensões que as constituem a partir de um ponto de entrada particular (um acontecimento, importante ou obscuro, um relato de vida, uma rede de práticas específicas) e considerando não haver prática ou estrutura que não seja produzida pelas representações, contraditórias e em confronto, pelas quais os indivíduos e os grupos dão sentido ao mundo que é o deles (CHARTIER, 1991, p. 06).
} 
Deste modo, as reflexões provenientes deste trabalho apontaram para a alimentação e as festividades como fatores culturais nas quais verificam-se a existência de estreitas relações entre o meio rural, a gastronomia e as inter-relações pessoais, juntamente com os laços históricos da colonização italiana, na constituição cultural da identidade dos habitantes e seus parentescos no município de Silveira Martins-RS.

\section{Referências Bibliográficas}

ÁlVAREZ, Marcelo; PINOTTI, Luisa. Anticipos de la cocina del siglo XXI. In: A la mesa: ritos y retos de la alimentación argentina. Buenos Aires: Grijalbo, 2000. p.257-279.

ARQUIVO PÚBLICO E HISTÓRICO MUNICIPAL DE BENTO GONÇALVES, Bento Gonçalves: Ontem e hoje. Porto Alegre: Evangraf, 1994.

CHARTIER, Roger. O mundo como representação. Estudos Avançados, São Paulo, 11(5), p.173-191, 1991. Disponível em: http:/www.scielo.br/pdf/ea/v5n11/v5n11a10.pdf.

CLAVAL, P. Geografia Cultural. 2. ed. Florianópolis: Ed. da UFSC, 2001.

CRISTÓVÃO, A. Mundo Rural: Entre as representações (dos urbanos) e os benefícios reais (para os rurais). In: Riedl, M.; Almeida, J. A.; Viana, A. L. B. (2002). Turismo rural: Tendências e sustentabilidade. Santa Cruz do Sul: EDUNISC. p. 81-116.

DAMATTA, R. Sobre o simbolismo da comida no Brasil. O correio da Unesco, Rio de Janeiro, 15 (7), p.22-23, 1987.

FAGLIARI, G. S. Turismo e Alimentação. Análises introdutórias. São Paulo: Roca, 2002.

FISCHLER, C. La formación del gusto. In: El (h)omnívoro: el gusto, la cocina y el cuerpo. Barcelona: Anagrama, 1995. p.88-113.

FLORES E SILVA, Y. Alimentação e transformações culturais no meio rural: uma discussão sobre gastronomia rural e segurança alimentar. In: Almeida, J. A.; Souza, M. de. (2006). Turismo Rural: Patrimônio, cultura e legislação. Santa Maria: Facos. p. 187-206.

FLORES, M. A identidade cultural do território como base de estratégias de desenvolvimento: uma visão do estado da arte. InterCambios, 6 (64), 2006. Disponível em: $<$ http://www.rimisp.org/getdoc.php?docid=3736>. Acesso em: 22 jul. 2007.

FLANDRIN, Jean-Louis; MONTANARI, Massimo (Dir.). História da alimentação. São Paulo: Estação Liberdade, 1998. A humanização das condutas alimentares. p.26-35.

GARINE, I. de. Alimentação, culturas e sociedades. O correio da Unesco, Rio de Janeiro, 15 (7), p.4-7, 1987. 
HENRIQUES, M. S. Comunicação e estratégias de mobilização social. Belo Horizonte: Genius, 2002.

ITAQUI, J. Quarta colônia: Inventários Técnicos. Santa Maria: Condesus Quarta Colônia, 2002.

MASINA, R. Introdução ao estudo do turismo. Conceitos básicos. Porto Alegre: Mercado Aberto, 2002.

MILLÁN, A. Malo para comer, bueno para pensar: crisis en la cadena socioalimentaria. In: GRACIA A., M. (Coord.). Somos lo que comemos: estudios de alimentación y cultura en España. Barcelona: Ariel, 2002. p.277-295.

PESSOAS E LUGARES: JORNAL DE ANIMAÇÃO DA REDE PORTUGUESA LEADER, Gastronomia e identidade territorial, II Série, n. 26. Janeiro/Fevereiro Portugal: Lisboa, 2006. Disponível em: <http://www.idrha.pt/pl/jornalp126.pdf >. Acesso em: 25 jul. 2007.

RAMOS, M. O. A "comida da roça" ontem e hoje: Um estudo etnográfico dos saberes e práticas alimentares de agricultores de Maquine (RS). 2007. 172p. Dissertação (Mestrado em Desenvolvimento Rural) - Universidade Federal do Rio Grande do Sul, Porto Alegre, 2007.

SANTOS, M.; SILVEIRA, M. L. O Brasil. Território e sociedade no início do século XXI. São Paulo: Record, 2003.

SOUZA, C. F. Contrastes regionais e formações urbanas. Porto Alegre: Ed. da UFRGS, 2000 .

TORO, J. B.; WERNWCK, N. M. D. Mobilização social: Um modo de construir a democracia e a participação. Brasília: Ministério da Justiça, 1997. 